thousand dollars in machincry to work beets that do not exist. No farmers will raise beets until a sugar factory is ready to buy them.

This almost impassable gap between the capitalist who cannot raise the beets and the farmer who cannot make the sugar, has at last been bridged by the Maine Beet Sugar Company, which last year made 183,000 pounds of beet sugar, is now erecting the best European machinery, and has contracted with 1700 farmers for 1250 acres of sugar bects. Under the stimulus of a State bounty of one cent per pound on the sugar produced, this company has leased the Forest City Sugar Refinery in Portland, Me., for the fall and winter months, and hats expended a large sum in additional machinery. Next fall there is reason to believe that the experiment of making beet sugar in America will be fully and fairly tried in Maine. Indeed, the question will be reluced to this: "Can beets be raised by American farmers in quantities and at prices which will justify their conversion into beet sugar?" The result of the experiment will be awaited with general interest.Boston Advertiser.

\title{
ON THE USE OF DETERMINING SLAG DENSITIES IN SMELTING.
}

By Thomas Macfarlane.

A paper read at the Pittsburgh Meeting of the American Institute of Mining Engineers, May, 1879.

In smelting copper, lead and silver ores, it is scarcely possible in every case to make analyses of the various parcels of ore, with the view of combining these and the fluxes, so accurately as to yield, in the furnace, slags of exactly the most favorable composition. This is even more difficult with ores which require previous calcination, or with mattes which have been roasted in heaps. Even in cases where the greatest pains have been taken and the most elaborate calculations made beforehand, it frequently happens that variations in the working of the furnace interfere with the result so much desired. Generally, the practical metallurgist must be content with ascertaining the average composition of his ores and fluxes, making a calculation once for all as to the most advantageous mixture, and leaving slight changes in its composition to be taken care of as it is passing through the furnace.

Whole No. Vox. CVIII.-(ThIrd Series, Vol. Ixxviii.) 
The various products then afford him the best material whereon to base his judgment as to the manner in which his smelting mixture and the furnace are working. Of course the character of the slag is one of his chief guides, but it is not always possible from its outward characters alone to form a correct judgment as to its composition. Neither would it be possible or practicable to apply chemical analysis for this purpose, as it would be impossible to wait for its results while working a furnace.

Abich was, I believe, the first to point out the relation existing between the composition of voleanic rocks and their densities, and to show that the latter being ascertained, very correct conclusions might be drawn as to their content of silica. The general rule is that the most siliceous rocks are the lightest, and the most basic have the highest specific gravity. It occurred to me that by determining the density of slags it might be possible to judge more accurately of their nature than by observing merely their superficial appearance. This plan was first applied at the Wyandotte Silver Smelting and Refining Works in Scptember, 1877, when siliceous silver ores and galenas from Georgetown, Colorado, were being treated. Mr. F. H. Williams determined the following densities and silica contents of the slags from these ores:

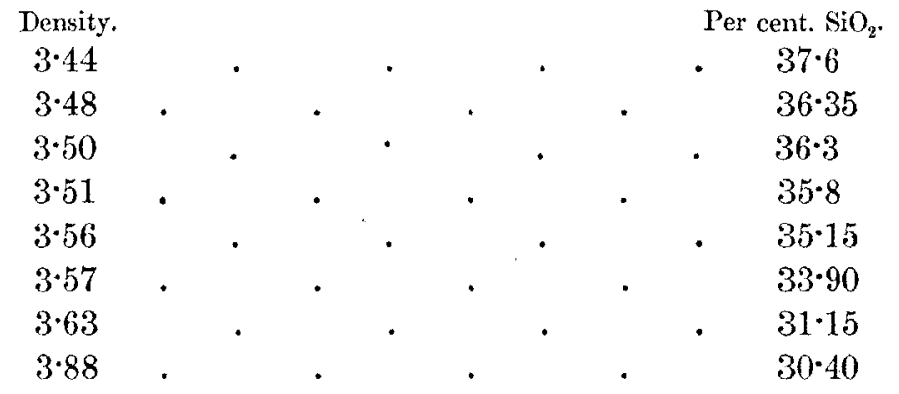

In July and August, 1878, Mr. S. B. Wight made the following examinations of three slags from one and the same smelting campaign during which Western ores were being treated:

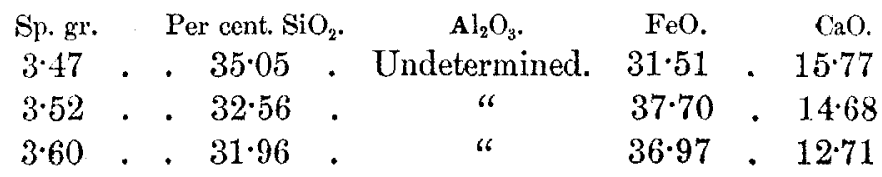

The gradual increase of density as the silica decreases in both these 
series of examinations will be apparent. But the rule is not absolute, and is only applicable where the relative quantity of the different bases in a slag remains the same. In smelting ferruginous ores and lead and copper mattes the quantity of protoxide of iron in the slag in proportion to the other bases is usually greater, and this increases the density, although the percentage of silica may remain the same. A slag from smelting lead matte gave, on examination by Mr. S. B. Wight, as follows :

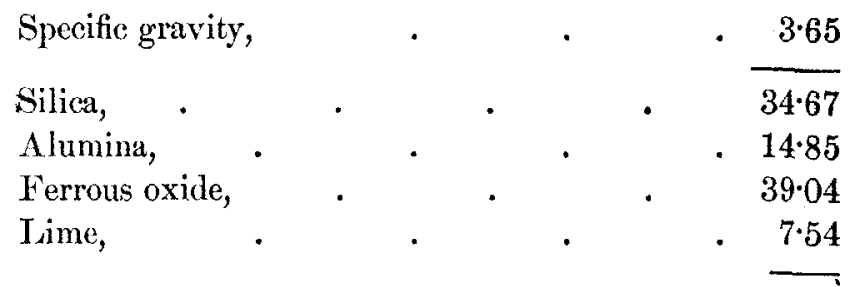

If this example is compared with the first in the last-mentioned series it will be found that an increase of 7.53 per cent. in the ferrous oxide, while the silica remains nearly the same, causes a considerable increase in density. The following determinations are further generally illustrative of the increase of density in slags as their percentage of silica decreases:

\begin{tabular}{|c|c|c|c|c|c|}
\hline $\begin{array}{l}\text { Where produced. } \\
\text { Iron Blast Furnace, Wyandotte, }\end{array}$ & $\begin{array}{l}\text { Sp. gr. } \\
2 \cdot 85\end{array}$ & $\begin{array}{l}\mathrm{SiO}_{2} \\
55^{\circ}\end{array}$ & $\begin{array}{l}\mathrm{Al}_{2} \mathrm{O}_{3} \\
\text { Un }\end{array}$ & $\begin{array}{l}\text { FeO. } \\
\text { leterm }\end{array}$ & $\begin{array}{l}\mathrm{CaO} \text {. } \\
\text { ned. }\end{array}$ \\
\hline Copper Works, Detroit, & . 3.04 & $43 \bullet 31$ & $26 \cdot 22$ & & $27 \cdot 40$ \\
\hline Germania Works, Utah, & $3 \cdot 81$ & $28 \cdot 01$ & Und. & $48 \cdot 10$ & $12 \cdot 37$ \\
\hline Fureka Consolidated Works, Nevada, & - $4 \cdot 18$ & $26 \cdot 47$ & " & $61 \cdot 62$ & 273 \\
\hline Wyandotte Rolling Mills ("heating slag" & $4,4 \cdot 29$ & $25 \cdot 49$ & “ & $75 \cdot 06$ & \\
\hline
\end{tabular}

Some of these determinations are by Dr. Hermann Hahn, others by Mr. S. B. Wight.

In practically making use of the slag densities for regulating the smelting at Wyandotte Silver Smelting and Refining Works, Jolly's spring balance (described at page 59 of Brush's Determinative Mineralogy) was found of great service. Five minutes only are used in making, by its use, two determinations of the density of a slag, and then it is found easy to decide whether any change in the smelting charge is necessary. The smelting of ore goes on regularly and eleanly when the specific gravity of the slag is kept between 3.6 and 3.8 . Water-jacket furnaces are used, with six tuyeres, and a height from these to the charging-door of $\mathbf{1 2}$ feet. The crucible of each 
furnace is 18 inches deep, and furnished with a tapping-hole at the bottom, besides the usual "lead-well" and slag-spout. The tapping ockasions no difficulty, and so long as the slag is not allowed to become too heavy no incerstations are deposited in the funace, which is easily eleaned ont at the end of each campaign. The charging is managed in the following way: The smelting mixture is made up of ore and fluxes, and is calculated to yield a slag containing 32 per cent. silica. The slag necesiary to kep the charge open is added separately in the proportion of about one-third of the smelting mixture. The slar used is unclean slag from previous campaigns and puddling slag or heating slag (frisehschlucke) from the rolling mills. When the furnace yields a slag of greater density than $3 \cdot 8$ the proportion of rolling-mill slag is decreased. The latter is on the other hand increased when the slag produced is lighter than 36 . By ascertaining the specific gravity of the slags frequently, and altering the charge in the mamer described, the furnaces are found to work regularly and satisfactorily.

It is not supposed that the exact figures above given will be found of great value in other smelting works, or that by attending only to the composition of slags in smelting it will be possible to do the best of work. The metallurgist has very many points to consider at one and the same time while conducting smelting operations, and the object of this paper is merely to direct his attention to one of these points and to indicate a mole of ascertaining approximatively the amount of silica in slags with comparative ease and accuracy.

\section{Transformations of Nervous Phenomena.-In reviewing the} affections and the nervous phenomena which are propagated by a transmission and a trausformation of motion, from simple yawning to epilepsy, fascination, panic, etc., J. Rambosson formulates the following general principle: A purely physical movement may be transformed into a physiological and into a psychic or cerebral movement by simple transmission to special portions of the system, and reciprocally, a psychic movement can be transformed into a physiological and into a physical movement by simple transmission to a different portion of the system, and that without losing its character; for it reproduces the same phenomena, after all these transmissions and transformations.-Comptes Rendus. 